\title{
Endothelial nitric oxide synthase gene polymorphisms and the risk of silent brain infarction
}

\author{
JIHWAN SONG ${ }^{1 *}$, OK JOON KIM ${ }^{2 *}$, HYUN SOOK KIM ${ }^{2}$, SU JIN BAE ${ }^{3}$, \\ SUN PYO HONG ${ }^{4}$, DOYEUN OH ${ }^{3}$ and NAM KEUN KIM ${ }^{3}$ \\ ${ }^{1}$ CHA Stem Cell Institute, School of Medicine, CHA University, Seoul 135-081; ${ }^{2}$ Department of Neurology; ${ }^{3}$ Institute for \\ Clinical Research, Bundang CHA General Hospital, School of Medicine, CHA University, \\ Seongnam 463-712; ${ }^{4}$ Genematrix Inc., Yongin 449-913, Korea
}

Received December 22, 2009; Accepted February 25, 2010

DOI: 10.3892/ijmm_00000410

\begin{abstract}
Silent brain infarction (SBI), a unique cerebrovascular disorder, is frequently detected on magnetic resonance imaging (MRI) of apparently healthy elderly persons, and it is known to increase the risk of stroke and other related diseases. Although detailed mechanisms of SBI pathogenesis have yet to be determined, recent studies suggest that SBI is significantly influenced by genetic factors. In this study, we investigated polymorphisms in the endothelial nitric oxide synthase $(e N O S)$ gene (i.e., -786T $>\mathrm{C}, 4 \mathrm{a} 4 \mathrm{~b}$ and $894 \mathrm{G}>\mathrm{T}$ ) as possible risk factors for SBI. We enrolled 269 patients with SBI and 234 control subjects and examined their fasting plasma homocysteine and folate levels, and analyzed for eNOS polymorphisms and haplotypes. The prevalence of SBI was shown to be significantly higher in patients with the eNOS 894GT genotype (OR, 2.00; 95\% CI, 1.30-3.08) and 894GT+TT genotype (OR, 2.05; 95\% CI, 1.34-3.16), compared with the $894 \mathrm{GG}$ genotype. However, in the case of $-786 \mathrm{~T}>\mathrm{C}$ and $4 \mathrm{a} 4 \mathrm{~b}$ polymorphisms, no significant difference was observed between SBI patients and normal subjects. Interestingly, we found that the prevalence of SBI can increase twice as high when either $-786 \mathrm{~T}>\mathrm{C}$ or $4 \mathrm{a} 4 \mathrm{~b}$ polymorphism was combined with $894 \mathrm{G}>\mathrm{T}$ polymorphism, -786TC+CC/ 894GT+TT (OR, 3.83; 95\% CI, 1.24-11.80) and 4a4b+4a4a/894GT+TT (OR, 4.08; 95\% CI, 1.34-12.40), respectively. According to haplotype analysis, we found that three haplotypes (-786T-4b-894G, -786T-4b-894T and $-786 \mathrm{C}-4 \mathrm{a}-894 \mathrm{~T}$ ) were shown to be significantly different between SBI patients and control subjects. These results indicate that eNOS polymorphisms and haplotypes serve as risk factors for SBI, and three different polymorphic loci in
\end{abstract}

Correspondence to: Dr Nam Keun Kim, Institute for Clinical Research, School of Medicine, CHA University, 351 Yatap-dong, Bundang-gu Seongnam 463-712, Korea

E-mail: nkkim@cha.ac.kr

*Contributed equally

Key words: endothelial nitric oxide synthase, silent brain infarction, polymorphism, haplotype, risk factors the eNOS gene play interactively, thereby leading to synergistic effects for the generation of SBI.

\section{Introduction}

Silent brain infarction (SBI) is defined as a unique form of cerebral infarction, which can be evident by brain imaging but does not exhibit overt clinical manifestations, such as rapidly developing clinical symptoms and signs of focal and at times global loss of brain function. It is relatively common in the geriatric population with a prevalence of $10-40 \%$, which gradually increases with age (1-6). Although the clinical significance of SBI has received much attention in recent years, detailed mechanisms of its pathogenesis have yet to be determined. Recent studies strongly suggest that SBI can be significantly influenced by many risk factors, such as hypertension (5), homocysteine $(7,8)$, cigarette smoking (9), and metabolic syndrome (10). However, relatively little is known about the genes responsible for causing SBI. Among various candidate genes that might be involved in SBI pathogenesis, we have first focused on the eNOS gene, which is known to be responsible for causing hyperhomocysteinemia that was found to be a risk factor for SBI in our previous study (8).

eNOS, an essential enzyme catalyzing the formation of soluble NO from L-arginine, possesses various physiological roles, including the maintenance of basal cerebral blood flow, cerebral vasodilation, vascular integrity, as well as the inhibition of smooth muscle proliferation (11-13). Therefore, the dysregulation of eNOS can lead to atherosclerosis, ischemic stroke, and various other vessel diseases (14-18). Related to these pathogenic conditions, three representative polymorphisms of the eNOS gene have been identified: i) -786T $>\mathrm{C}$ within the 5'-flanking region (14); ii) 27-bp deletion(a)/insertion(b) within the intron 4 (collectively designated as '4a4b') (19); iii) $894 \mathrm{G}>\mathrm{T}$ within the exon 7 (20-22).

Considering the significance of SBI, which is known to increase the risk of developing into serious vascular diseases, such as stroke and dementia, there has been no epidemiological study on the eNOS polymorphisms in the SBI patients to our knowledge, although very few polymorphic studies of other genes have been reported $(8,23-25)$. Therefore, in the present study, we investigated the role of polymorphisms in the 
eNOS gene $(-786 \mathrm{~T}>\mathrm{C}, 4 \mathrm{a} 4 \mathrm{~b}$ and $894 \mathrm{G}>\mathrm{T})$ as a risk factor for SBI. Interestingly, we found combinatorial effects caused by interactions among three loci, which lead to a significant increase in the risk of SBI. We have also carried out a haplotype analysis on three loci in SBI patients.

\section{Materials and methods}

Subjects. The study population was composed of 269 patients with SBI (124 men, 145 women) and 234 control subjects (116 men, 118 women). The patients were enrolled from July 1, 2000 to February 28, 2004 in the Neurology Department at Bundang CHA General Hospital by consecutive referral. A diagnosis of SBI was made by MRI examination and by agreement between two independent experienced neurologists. SBI was excluded when an agreement was not reached and patients with cerebral hemorrhage were excluded in advance. All patients underwent a brain MRI scan and electrocardiography, and the criteria for selecting SBI patients were used as we have previously reported (8).

For control subjects, we selected healthy individuals matched for sex and age within 5 years, from patients undergoing health examinations at our hospitals, which included biochemistry, electrocardiogram, and brain MRI, during the same period, and have no history of cerebrovascular disease or myocardial infarction. Exclusion criteria were the same as those used in the patient group, as mentioned above. Among the study population, some patients were diagnosed as having hypertension, diabetes mellitus or hyperlipidemia after the diagnostic criteria were fulfilled at the time of enrollment. Hypertension was defined as systolic pressure $>140 \mathrm{mmHg}$ and/or diastolic pressure $>90 \mathrm{mmHg}$ on more than one occasion, according to the Joint National Committee (JNC 7) report guidelines and currently taking hypertensive medication. Diabetes was defined as fasting plasma glucose $>126 \mathrm{mg} / \mathrm{dl}$ $(7.0 \mathrm{mmol} / \mathrm{l})$ and included patients with diabetic medication $(26,27)$.

Informed consent was obtained from all study participants after being given a full explanation of the study. In this study, all study populations were in Hardy-Weinberg equilibrium. The institutional review board of Bundang CHA Hospital approved this genetic study in June 2000.

Laboratory analysis. Venous blood samples were collected in tubes containing genetic analysis on eNOS polymorphisms and was carried out using polymerase chain reaction (PCR)restriction fragment length polymorphism method, according to the method of Wilcox et al (28). Plasma homocysteine levels were determined as total homocysteine by fluorescence polarization immunoassay (FPIA), according to the manufacturer's instructions (IMx, Abbott Laboratories, Abbott Park, IL).

Statistical analysis. To estimate the magnitude of the association between $e N O S$ polymorphisms and SBI, we used odds ratio (OR) and $95 \%$ confidence interval (CI). For crude analysis of baseline characteristics, we used the Chi test for categorical data (gender, hypertension, diabetes mellitus, and hyperlipidemia), and the two-sample t-test for continuous data (age and homocysteine). For multivariate analysis, we used logistic
Table I. Demographic and clinical characteristics of SBI patients and controls.

\begin{tabular}{|c|c|c|c|}
\hline Characteristic & $\begin{array}{l}\text { Patients } \\
(\mathrm{n}=269)\end{array}$ & $\begin{array}{l}\text { Controls } \\
(n=234)\end{array}$ & P-value \\
\hline Male (\%) & $124(46.1)$ & $116(49.6)$ & 0.474 \\
\hline $\begin{array}{l}\text { Age (years, } \\
\text { mean } \pm \text { SD) }\end{array}$ & $62.22 \pm 11.90$ & $59.55 \pm 11.75$ & 0.012 \\
\hline $\begin{array}{l}\text { tHcy }(\mu \mathrm{mol} / 1, \\
\text { mean } \pm \mathrm{SD})\end{array}$ & $11.30 \pm 6.35$ & $9.68 \pm 3.96$ & 0.001 \\
\hline Hypertension (\%) & $142(52.8)$ & $118(50.4)$ & 0.655 \\
\hline Diabetes mellitus (\%) & $38(14.1)$ & $42(17.9)$ & 0.272 \\
\hline Hyperlipidemia (\%) & $88(32.7)$ & $43(18.4)$ & 0.000 \\
\hline
\end{tabular}

tHcy, total plasma homocysteine; SD, standard deviation.

regression to adjust for possible confounders, i.e., age, gender, hypertension, diabetes mellitus and hyperlipidemia. Analysis was performed using SPSS for Windows, version 11.0 (SPSS Inc., Chicago, IL, USA). Haplotype frequencies for multiple loci were estimated using the Expectation-Maximization (EM) algorithm with the SNPAlyze program (Dynacom, Yokohama, Japan, http://www.dynacom. co.jp/).

\section{Results}

The demographic characteristics of 269 SBI patients and 234 control patients are shown in Table I. Each population consists of 46.1 and $49.6 \%$ males, and the mean age of each population was $62.22 \pm 11.90$ and $59.55 \pm 11.75$ years, respectively. Between the two groups, there was no significant difference in gender composition but significant difference was detected in age composition, for which adjustment was made in the subsequent analyses (Table II). Nevertheless, there were no overall changes in values even after adjustments were made. Interestingly, as shown in Table I, we observed significant differences according to the levels of total plasma homocysteine and in hyperlipidemia patients, but no significant difference was observed in hypertension or diabetes mellitus (DM) patients.

We first investigated the eNOS gene -786T $>\mathrm{C}, 4 \mathrm{a} 4 \mathrm{~b}$ and $894 \mathrm{G}>\mathrm{T}$ polymorphisms, the genotype distribution and allele frequency in SBI patients and controls are shown in Table II. The distribution of the eNOS -786T >C, 4a4b, and 894G>T genotypes and allele frequencies in patients and controls were compatible with Hardy-Weinberg's equilibrium. As for the eNOS $894 \mathrm{G}>\mathrm{T}$ polymorphism, OR at $95 \% \mathrm{CI}$ of $894 \mathrm{GT}$ and $894 \mathrm{GT}+\mathrm{TT}$ were 2.00 (1.30-3.08) and 2.05 (1.34-3.16), respectively, showing significant differences, compared to 894GG. However, there were no significant differences in either $-786 \mathrm{~T}>\mathrm{C}$ or $4 \mathrm{a} 4 \mathrm{ab}$ polymorphisms between the SBI patient and control groups. We also examined the values of adjusted OR (AOR), according to age, gender, HTN, DM and hyperlipidemia. However, no significant differences were detected between AOR and crude OR (COR).

We next carried out combinatorial analysis on the effects of different genotypes in eNOS polymorphisms, i.e., eNOS 
Table II. eNOS genotype distributions in SBI patients and controls.

\begin{tabular}{|c|c|c|c|c|c|c|}
\hline Genotype & Patients $(n=265)$ & Controls $(n=232)$ & COR & $(95 \% \mathrm{CI})$ & AOR & $(95 \% \mathrm{CI})$ \\
\hline -786TT (\%) & $218(82.3)$ & $193(83.2)$ & 1.00 & - & - & - \\
\hline -786TC (\%) & $43(16.2)$ & $39(16.8)$ & 0.98 & $(0.61-1.57)$ & 0.78 & $(0.43-1.41)$ \\
\hline -786CC (\%) & $4(1.5)$ & $0 \quad(0.0)$ & - & - & - & - \\
\hline -786TC+CC (\%) & $47(17.7)$ & $39(16.8)$ & 1.07 & $(0.67-1.70)$ & 0.84 & $(0.47-1.51)$ \\
\hline $\mathrm{C}$ allele & 0.096 & 0.084 & & & & \\
\hline $4 \mathrm{~b} 4 \mathrm{~b}(\%)$ & $214(80.8)$ & $181(78.0)$ & 1.00 & - & - & - \\
\hline $4 \mathrm{a} 4 \mathrm{~b}(\%)$ & $43(16.2)$ & $41(17.7)$ & 0.89 & $(0.55-1.42)$ & 0.60 & $(0.32-1.09)$ \\
\hline $4 \mathrm{a} 4 \mathrm{a}(\%)$ & $8 \quad(3.0)$ & $0 \quad(0.0)$ & - & - & - & - \\
\hline $4 a 4 b+4 a 4 a(\%)$ & $51(19.2)$ & $41(17.7)$ & 1.05 & $(0.67-1.66)$ & 0.73 & $(0.41-1.30)$ \\
\hline A allele & 0.111 & 0.089 & & & & \\
\hline 894GG (\%) & $185(69.8)$ & $190(81.9)$ & 1.00 & - & - & - \\
\hline 894GT (\%) & $78(29.4)$ & $40(17.2)$ & 2.00 & $(1.30-3.08)$ & 2.27 & $(1.34-3.83)$ \\
\hline 894TT (\%) & $2(0.8)$ & $0 \quad(0.0)$ & - & - & - & - \\
\hline 894GT+TT (\%) & $80(30.2)$ & $40(17.2)$ & 2.05 & $(1.34-3.16)$ & 2.35 & $(1.39-3.96)$ \\
\hline $\mathrm{T}$ allele & 0.165 & 0.086 & & & & \\
\hline
\end{tabular}

Numbers of corresponding controls for $-786 \mathrm{~T}>\mathrm{C}, 4 \mathrm{a} 4 \mathrm{~b}, 894 \mathrm{G}>\mathrm{T}$ polymorphisms were 232 , 222, and 230, respectively. Adjusted odds ratio (AOR) was made according to the combinations of age, gender, hypertension, DM and hyperlipidemia. COR, crude odds ratio; CI, confidence interval; DM, diabetes mellitus.

Table III. Combinatorial effects observed in SBI patients and controls, according to the genotypes in $e N O S$ polymorphisms $(e N O S-786 \mathrm{~T}>\mathrm{C}, 4 \mathrm{a} 4 \mathrm{~b}$ and $894 \mathrm{G}>\mathrm{T})$.

\begin{tabular}{|c|c|c|c|c|c|c|}
\hline Genotype & Patients (\%) & Controls (\%) & COR & $(95 \% \mathrm{CI})$ & AOR & $(95 \% \mathrm{CI})$ \\
\hline$-786 / 4 a 4 b$ & $(n=263)$ & $(n=220)$ & & & & \\
\hline $\mathrm{TT} / 4 \mathrm{~b} 4 \mathrm{~b}$ & $211(80.2)$ & $178(80.9)$ & 1.00 & - & - & - \\
\hline $\mathrm{TT} / 4 \mathrm{a} 4 \mathrm{~b}+4 \mathrm{a} 4 \mathrm{a}$ & $6 \quad(2.3)$ & $4(1.8)$ & 1.26 & $(0.35-4.56)$ & 0.65 & $(0.15-2.90)$ \\
\hline $\mathrm{TC}+\mathrm{CC} / 4 \mathrm{~b} 4 \mathrm{~b}$ & $1 \quad(0.4)$ & $1 \quad(0.5)$ & 0.84 & $(0.05-13.60)$ & 0.81 & $(0.05-13.49)$ \\
\hline $\mathrm{TC}+\mathrm{CC} / 4 \mathrm{a} 4 \mathrm{~b}+4 \mathrm{a} 4 \mathrm{a}$ & $45(17.1)$ & $37(16.8)$ & 1.03 & $(0.64-1.66)$ & 0.72 & $(0.39-1.33)$ \\
\hline$-786 / 894$ & $(n=263)$ & $(n=230)$ & & & & \\
\hline $\mathrm{TT} / \mathrm{GG}$ & $152(57.8)$ & $155(67.4)$ & 1.00 & - & 1.00 & - \\
\hline $\mathrm{TT} / \mathrm{GT}+\mathrm{TT}$ & $65(24.7)$ & $36(15.7)$ & 1.84 & $(1.16-2.93)$ & 2.11 & $(1.21-3.70)$ \\
\hline $\mathrm{TC}+\mathrm{CC} / \mathrm{GG}$ & $31(11.8)$ & $35(15.2)$ & 0.90 & $(0.53-1.54)$ & 0.68 & $(0.35-1.32)$ \\
\hline $\mathrm{TC}+\mathrm{CC} / \mathrm{GT}+\mathrm{TT}$ & $15 \quad(5.7)$ & $4 \quad(1.7)$ & 3.82 & $(1.24-11.80)$ & 3.59 & $(0.91-14.08)$ \\
\hline $4 a 4 b / 894$ & $(n=263)$ & $(n=220)$ & & & & \\
\hline $4 b 4 b / G G$ & $149(56.7)$ & $143(65.0)$ & 1.00 & - & 1.00 & - \\
\hline $4 \mathrm{~b} 4 \mathrm{~b} / \mathrm{GT}+\mathrm{TT}$ & $63(24.0)$ & $36(16.4)$ & 1.68 & $(1.05-2.69)$ & 1.96 & $(1.11-3.47)$ \\
\hline $4 a 4 b+4 a 4 a / G G$ & $34(12.9)$ & $37(16.8)$ & 0.88 & $(0.52-1.48)$ & 0.59 & $(0.30-1.16)$ \\
\hline $4 \mathrm{a} 4 \mathrm{~b}+4 \mathrm{a} 4 \mathrm{a} / \mathrm{GT}+\mathrm{TT}$ & 17 (6.4) & $4(1.8)$ & 4.08 & $(1.34-12.40)$ & 3.80 & $(0.95-15.28)$ \\
\hline
\end{tabular}

Adjusted OR (AOR) was made according to the combinations of age, gender, hypertension, DM and hyperlipidemia. OR, odds ratio; CI, confidence interval; DM, diabetes mellitus; COR, crude OR.

$-786 \mathrm{~T}>\mathrm{C}, 4 \mathrm{a} 4 \mathrm{~b}$ and $894 \mathrm{G}>\mathrm{T}$. When the effects of $-786 \mathrm{~T}>\mathrm{C}$ and 4a4b polymorphisms were combined, significant differences were observed in the genotypes -786TT/894GT+TT (COR, $1.84 ; 95 \% \mathrm{CI}, 1.16-2.93)$ and $-786 \mathrm{TC}+\mathrm{CC} / 894 \mathrm{GT}+\mathrm{TT}$ (COR, 3.82; 95\% CI, 1.24-11.8), compared to those examined individually (Table III). A similar phenomenon was detected in the genotypes $4 \mathrm{~b} 4 \mathrm{~b} / 894 \mathrm{GT}+\mathrm{TT}$ (COR, 1.68; 95\% CI, 1.05-2.69) and 4a4b+4a4a/894GT+TT (COR, 4.08; 95\% CI,
1.34-12.4) when the effects of $4 \mathrm{a} 4 \mathrm{~b}$ and $894 \mathrm{G}>\mathrm{T}$ polymorphisms were combined (Table III). Interestingly, in the case of AOR, corresponding combined genotypes also exhibited increased values in both -786/894 (2.11 and 3.59) and 4a4b/894 (1.96 and 3.80) polymorphisms. However, with respect to the values for $95 \%$ CI in AOR, significance was observed in $\mathrm{TT} / \mathrm{GT}+\mathrm{TT}$ and 4a4b/GT+TT genotypes, but no significance was detected in TC+CC/GT+TT and $4 \mathrm{a} 4 \mathrm{~b}+4 \mathrm{a} 4 \mathrm{a} / \mathrm{GT}+\mathrm{TT}$ 
Table IV. Frequencies of eNOS -786T $>C$, 4a $4 b$ and $894 G>T$ haplotypes in SBI patients and controls.

\begin{tabular}{lcccc}
\hline $\begin{array}{l}\text { eNOS } \\
-786 / 4 \mathrm{a} 4 \mathrm{~b} / 894\end{array}$ & Overall & Patients & Controls & P-value \\
\hline T-4b-G & 0.778 & 0.748 & 0.814 & 0.014 \\
T-4b-T & 0.116 & 0.138 & 0.091 & 0.024 \\
C-4a-G & 0.080 & 0.077 & 0.084 & 0.703 \\
T-4a-G & 0.013 & 0.016 & 0.009 & 0.327 \\
C-4a-T & 0.009 & 0.016 & $7.42 \mathrm{E}-7$ & 0.008 \\
C-4b-G & 0.002 & 0.002 & 0.002 & 0.905 \\
T-4a-T & 0.002 & 0.003 & 0.0 & 0.263 \\
\hline
\end{tabular}

genotypes. However, in the latter case, it was found that the values can be misleading, since AORs for individual variables were shown to be significant in most cases, with a few exceptions (data not shown). Notably, it was shown that the 894GT+TT genotype may confer synergistic effects in OR values when combined with $-786 \mathrm{TC}+\mathrm{CC}(\mathrm{COR}, 1.07 \rightarrow 3.82$; AOR, $0.84 \rightarrow 3.59)$ or $4 \mathrm{a} 4 \mathrm{~b}+4 \mathrm{a} 4 \mathrm{a}$ (COR, $1.05 \rightarrow 4.08$; AOR, $0.73 \rightarrow 3.80$ ) genotypes, respectively (Tables II and III).

Since multiple loci may affect the functions of the eNOS gene, it will be important to perform a haplotype analysis, which would allow us to understand the effects of allelic changes on the $e N O S$ gene simultaneously. There are six alleles in the $e N O S$ gene, i.e., -786 (T or C), Intron 4(4a or 4b), 894(G or $\mathrm{T}$ ), and the combination of each allele can constitute eight haplotypes in theory. However, we detected only seven haplotypes in this study (Table IV). According to the hyplotype analysis, there were significant differences between SBI and control patients in three haplotypes, as follows: $\mathrm{T}-4 \mathrm{~b}-\mathrm{G}$ $(\mathrm{p}=0.014), \mathrm{T}-4 \mathrm{~b}-\mathrm{T}(\mathrm{p}=0.024)$ and $\mathrm{C}-4 \mathrm{a}-\mathrm{T}(\mathrm{p}=0.008)$. Among them, it is not surprising, the normal genotype, T-4b-G, displays a higher frequency in the control group.

\section{Discussion}

In recent years, clinical significance of SBI has had much attention, but the details of its pathogenesis and epidemiology are relatively unknown. At the genetic level, only a few genes have been reported as risk factors for SBI to date, which include apolipoprotein (a), methylenetetrahydrofolate reductase (MTHFR) angiotensinogen (AGT) and angiotensin II type 1 receptor (AT1R) $(23,24,29)$. We have recently studied the role of angiotensin-converting enzyme (ACE) polymorphism in the development of stroke and SBI, and found that it is associated with stroke but not with SBI (25).

In the present study, we demonstrate that the polymorphisms and haplotypes of the endothelial nitric oxide synthase $(e N O S)$ gene are involved in the development of SBI at a statistically significant level. It is well known that eNOS has various vascular functions, including maintenance of basal cerebral blood flow, cerebral vasodilation, vascular integrity and the inhibition of smooth muscle proliferation (11-13). Therefore, it is not surprising that the aberration of eNOS function can lead to critical vascular diseases, such as atherosclerosis, myocardial and acute cerebral infarction (14-18). As for the cerebrovascular diseases, it has been previously reported that $e N O S$ polymorphism is associated with cerebral infarction and small vessel diseases (14-16). Scarce previous knowledge exists whether it is related to SBI, another important type of cerebrovascular disease, but hard to diagnosed. In the present study, we carefully selected the SBI patients, according to the results of brain MRI and neurological examination.

According to our analysis, among three polymorphisms in the $e N O S$ gene (-786, 4a $4 \mathrm{~b}$ and 894$), 894 \mathrm{G}>\mathrm{T}$ polymorphism was shown to give a rise to the highest level of SBI risk (Table II). To coincide with our findings, it has been previously reported that $894 \mathrm{G}>\mathrm{T}$ polymorphism alone acts as a risk factor for brain infarction, especially in the lacunar type (16). Therefore, it is conceivable to propose that $894 \mathrm{G}>\mathrm{T}$ polymorphism in $e N O S$ gene may be involved in various types of cerebrovascular diseases. Interestingly, Hassan et al (14) previously reported a significant association between the eNOS 4a4b polymorphism and small vessel disease, but in the current study we showed that $894 \mathrm{G}>\mathrm{T}$ polymorphism is associated with SBI. To address the relationship between small vessel disease and SBI with respect to $e N O S$ polymorphism, further studies using larger sample populations will be needed.

In addition, we found that the prevalence of SBI increased significantly when either $-786 \mathrm{~T}>\mathrm{C}$ or $4 \mathrm{a} 4 \mathrm{~b}$ polymorphism was combined with $894 \mathrm{G}>\mathrm{T}$ polymorphism (Table III), indicating that three different polymorphic loci in the eNOS gene $(-786 \mathrm{~T}>\mathrm{C}, 4 \mathrm{a} 4 \mathrm{~b}$ and $894 \mathrm{G}>\mathrm{T})$ play interactively, thereby leading to synergistic effects for the generation of SBI. Lastly, we carried out haplotype analysis, in which significant differences were detected between SBI patients and control in three haplotypes (Table IV).

Taken together, the present study provides the first evidence that $e N O S$ polymorphisms and haplotypes are closely associated with the development of SBI. However, further studies using larger and heterogeneous populations would be of a great value to firmly validate their association with SBI, which will, in turn, provide a basis for developing a useful tool for diagnosing patients who have risk of developing SBI.

\section{Acknowledgements}

This work was partly supported by the Korea Research Foundation grant from the Korean Government (MOEHRD) (KRF-2008-521-E00121) and partly supported by Priority Centers Program through the National Research Foundation of Korea (NRF) funded by the Ministry of Education, Science and Technology (2009-0093821). The authors report no conflict of interest.

\section{References}

1. Kase CS, Wolf PA, Chodosh EH, Zacker HB, Kelly-Hayes M, Kannel WB, D'Agostino RB and Scampini L: Prevalence of silent stroke in patients presenting with initial stroke: the Farmingham study. Stroke 20: 850-852, 1989.

2. Jorgensen HS, Nakayama H, Raaschou HO, Gam J and Olsen TS: Silent infarction in acute stroke patients. Prevalence, localization, risk factors, and clinical significance: the Copenhagen stroke study. Stroke 25: 97-104, 1994.

3. Lee SC, Park SJ, Ki HK, Gwon HC, Chung CS, Byun HS, Shin KJ, Shin MH and Lee WR: Prevalence and risk factors of cerebral infarction in apparently normal adults. Hypertension 36 : 73-77, 2000. 
4. Corea F, Henon H, Pasquier F and Leys D: Silent infarcts in stroke patients: patient characteristics and effect on 2-year outcome. J Neurol 248: 271-278, 2001.

5. Vermeer SE, Koudstaal PJ, Oudkerk M, Hofman A and Breteler MMB: Prevalence and risk factors of silent brain infarcts in the population-based Rotterdam scan study. Stroke 33: 21-25, 2002.

6. Vermeer SE, Hollander M, van Dijk EJ, Hofman A, Koudstaal PJ and Breteler MM: Silent brain infarcts and white matter lesions increase stroke risk in the general population. The Rotterdam study. Stroke 34: 1126-1129, 2003.

7. Matsui T, Arai H, Yuzuriha T, Yao H, Miura M, Hashimoto S, Higuchi S, Matsushita S, Morikawa M, Kato A and Sasaki H: Elevated plasma homocysteine levels and risk of silent brain infarction in elderly people. Stroke 32: 1116-1119, 2001.

8. Kim NK, Choi BO, Jung WS, Choi YJ and Choi KG: Hyperhomocysteinemia as an independent risk factor for silent brain infarction. Neurology 61: 1595-1599, 2003.

9. Eguchi K, Kario K, Hoshide S, Hoshide Y, Ishikawa J Morinari M, Hashimoto T and Shimada K: Smoking is associated with silent cerebrovascular disease in a high-risk Japanese community-dwelling population. Hypertens Res 27: 747-754, 2004.

10. Kwon HM, Kim BJ, Lee SH, Choi SH, Oh BH and Yoon BW: Metabolic syndrome as an independent risk factor of silent brain infarction in healthy people. Stroke 37: 466-470, 2006.

11. Garg UC and Hassid A: Nitric oxide-generating vasodilators and 8-bromo-cyclic guanosine monophosphate inhibit mitogenesis and proliferation of cultured rat vascular smooth muscle cells. J Clin Invest 83: 1774-1777, 1989.

12. Kubes P, Suzuki M and Granger DN: Nitric oxide: an endogenous modulator of leukocyte adhesion. Proc Natl Acad Sci USA 88: 4651-4655, 1991

13. Wolf A, Zalpour C, Theilmeier G, Wang BY, Ma A, Anderson B, Tsao PS and Cooke JP: Dietary L-arginine supplementation normalizes platelet aggregation in hypercholesterolemic humans. J Am Coll Cardiol 29: 479-485, 1997.

14. Hassan A, Gormley K, O'Sullivan M, Knight J, Sham P, Vallance P, Bamford J and Markus $\mathrm{H}$ : Endothelial nitric oxide gene haplotypes and risk of cerebral small-vessel disease. Stroke 35: 654-659, 2004

15. Fatini C, Sofi F, Sticchi E, Gensini F, Gori AM, Fedi S, Lapini I, Rostagno C, Comeglio M, Brogi D, Gensini G and Abbate R: Influence of endothelial nitric oxide synthase gene polymorphisms (894G $>$ T, 4a4b, T-786C) and hyperhomocysteinemia on the predisposition to acute coronary syndromes. Am Heart J 147: 516-521, 2004

16. Elbaz A, Poirier O, Moulin T, Chédru F, Cambien F and Amarenco P: Association between the Glu298Asp polymorphism in the endothelial constitutive nitric oxide synthase gene and brain infarction. The GENIC Investigators. Stroke 31: 1634-1639, 2000 .

17. Ozüm U, Bolat N, Gül E and Ozdemir O: Endothelial nitric oxide synthase gene [G894T] polymorphism as a possible risk factor in aneurysmal subarachnoid haemorrhage. Acta Neurochir 150 $57-61,2008$.
18. Chen Y, Huang H, Zhou J, Doumatey A, Lashley K, Chen G, Agyenim-Boateng K, Eghan BA, Acheampong J, Fasanmade O, Johnson T, Akinsola FB, Okafor G, Oli J, Ezepue F, Amoah A, Akafo S, Adeyemo A and Rotimi CN: Polymorphism of the endothelial nitric oxide synthase gene is associated with diabetic retinopathy in a cohort of West Africans. Mol Vis 13: 2142-2147, 2007.

19. Wang XL, Sim AS, Badenhop RF, McCredie RM and Wilcken DE: A smoking-dependent risk of coronary artery disease associated with a polymorphism of the endothelial nitric oxide synthase gene. Nat Med 2: 41-45, 1996.

20. Markus HS, Ruigrok Y, Ali N and Powell JF: Endothelial nitric oxide synthase exon 7 polymorphism, ischemic cerebrovascular disease, and carotid athroma. Stroke 29: 1908-1911, 1998.

21. Lembo G, De Luca N, Battagli C, Iovino G, Aretini A, Musicco M, Frati G, Pompeo F, Vecchione C and Trimarco B: A common variant of endothelial nitric oxide synthase (Glu298Asp) is an independent risk factor for carotid atherosclerosis. Stroke 32: 735-740, 2001.

22. Szolnoki Z, Havasi V, Bene J, Komlósi K, Szöke D Somogyvári F, Kondacs A, Szabó M, Fodor L, Bodor A, Gáti I, Wittman I and Melegh B: Endothelial nitric oxide synthase gene interactions and the risk of ischemic stroke. Acta Neurol Scand 111: 29-33, 2005

23. Notsu Y, Nabika T, Park HY, Masuda J and Kobayashi S: Evaluation of genetic risk factors for silent brain infarction. Stroke 30: 1881-1886, 1999.

24. Kohara K, Fujisawa M, Ando F, Tabara Y, Niino N, Miki T and Shimokata H: MTHFR gene polymorphism as a risk factor for silent brain infarcts and white matter lesions in the Japanese general population: The NILS-LSA Study. Stroke 34: 1130-1135, 2003.

25. Hong SH, Park HM, Ahn JY, Kim OJ, Hwang TS, Oh D and Kim NK: ACE I/D polymorphism in Korean patients with ischemic stroke and silent brain infarction. Acta Neurol Scand 117: 244-249, 2008.

26. Chobanian AV, Bakris GL, Black HR, Cushman WC, Green LA Izzo JL Jr, Jones DW, Materson BJ, Oparil S, Wright JT Jr and Roccella EJ: The seventh report of the joint national committee on prevention, detection, evaluation, and treatment of high blood pressure: the JNC 7 report. JAMA 289: 2560-2572, 2003.

27. American Diabetes Association: Diagnosis and classification of diabetes mellitus. Diabetes Care 27: S5-S9, 2004

28. Wilcox JN, Subramanian RR, Sundell CL, Tracey WR, Pollock JS, Harrison DG and Marsden PA: Expression of multiple isoforms of nitric oxide synthase in normal and atherosclerotic vessels. Artheroscler Thromb Vasc Biol 17: 2479-2488, 1997.

29. Van Rijn MJ, Bos MJ, Isaacs A, Yazdanpanah M, Arias-Vásquez A, Stricker BH, Klungel OH, Oostra BA, Koudstaal PJ, Witteman JC, Hofman A, Breteler MM and van Duijn CM: Polymorphisms of the renin-angiotensin system are associated with blood pressure, atherosclerosis and cerebral white matter pathology. J Neurol Neurosurg Psychiatry 78: 1083-1087, 2007. 